\title{
Article \\ Determinants of In-Hospital Mortality in Elderly Patients Aged 80 Years or above with Acute Heart Failure: A Retrospective Cohort Study at a Single Rural Hospital
}

\author{
Yusuke Watanabe ${ }^{1, *}$, Kazuko Tajiri $^{2}{ }^{(D}$, Hiroyuki Nagata $^{1}$ and Masayuki Kojima ${ }^{3}$ \\ 1 Department of Internal Medicine, Hitachiomiya Saiseikai Hospital, 3033-3 Tagouchichou, Hitachiomiya, \\ Ibaraki 319-2601, Japan; m02067hn@jichi.ac.jp \\ 2 Department of Cardiology, Faculty of Medicine, University of Tsukuba, Tsukuba 305-8577, Japan; \\ ktajiri@md.tsukuba.ac.jp \\ 3 Department of Surgery, Hitachiomiya Saiseikai Hospital, Hitachiomiya 319-2256, Japan; \\ allforonekojima@gmail.com \\ * Correspondence: m04100yw@jichi.ac.jp; Tel.: +81-295-52-5151; Fax: +81-295-52-5725
}

Citation: Watanabe, Y.; Tajiri, K.; Nagata, H.; Kojima, M. Determinants of In-Hospital Mortality in Elderly Patients Aged 80 Years or above with Acute Heart Failure: A Retrospective Cohort Study at a Single Rural Hospital. J. Clin. Med. 2021, 10, 1468. https://doi.org/10.3390/jcm10071468

Academic Editor: Nuria Farre

Received: 11 February 2021

Accepted: 23 March 2021

Published: 2 April 2021

Publisher's Note: MDPI stays neutral with regard to jurisdictional claims in published maps and institutional affiliations.

Copyright: () 2021 by the authors. Licensee MDPI, Basel, Switzerland. This article is an open access article distributed under the terms and conditions of the Creative Commons Attribution (CC BY) license (https:// creativecommons.org/licenses/by/ $4.0 /)$.

\begin{abstract}
Heart failure is one of the leading causes of mortality worldwide. Several predictive risk scores and factors associated with in-hospital mortality have been reported for acute heart failure. However, only a few studies have examined the predictors in elderly patients. This study investigated determinants of in-hospital mortality in elderly patients with acute heart failure, aged 80 years or above, by evaluating the serum sodium, blood urea nitrogen, age and serum albumin, systolic blood pressure and natriuretic peptide levels (SOB-ASAP) score. We reviewed the medical records of 106 consecutive patients retrospectively and classified them into the survivor group $(n=83)$ and the non-survivor group $(n=23)$ based on the in-hospital mortality. Patient characteristics at admission and during hospitalization were compared between the two groups. Multivariate stepwise regression analysis was used to evaluate the in-hospital mortality. The SOB-ASAP score was significantly better in the survivor group than in the non-survivor group. Multivariate stepwise regression analysis revealed that a poor SOB-ASAP score, oral phosphodiesterase 3 inhibitor use, and requirement of early intravenous antibiotic administration were associated with in-hospital mortality in very elderly patients with acute heart failure. Severe clinical status might predict outcomes in very elderly patients.
\end{abstract}

Keywords: acute heart failure; elderly patients; SOB-ASAP score; phosphodiesterase 3 inhibitor; antibiotics

\section{Introduction}

Heart failure is one of the most common diseases worldwide and generally affects the elderly [1-3]. Elderly patients with heart failure are likely to have many comorbidities [2]. The prevalence of heart failure is on the rise due to the rapidly aging population [3,4]; in 2019 , the estimated number of individuals aged 65 years or above in Japan was approximately 36 million (28.4\% of the total population). Heart failure is the leading cause of mortality in Japan. Although several novel medications have been developed [5], therapeutic strategies for improving patients' prognoses are yet to be identified.

Previous studies have suggested that risk score systems are useful for predicting prognosis in inpatients and outpatients with heart failure [6-8]. Other studies have reported factors leading to in-hospital mortality, such as acute kidney injury, new-onset atrial fibrillation, and nutritional index [9-11]. However, most of these studies have focused on relatively younger populations than the Japanese elderly population, and very few studies have focused on the very elderly population $[12,13]$. The population of hospitalized patients with acute heart failure is aging, even in rural areas. Recently, a novel scoring system, the serum sodium, blood urea nitrogen, age and serum albumin, systolic blood pressure and natriuretic peptide level (SOB-ASAP) score, was developed in Japanese 
registries [14]. The SOB-ASAP score ranges from 0 to 14; the highest score indicates a high in-hospital mortality rate [14].

This study aimed to reveal other determinants of in-hospital mortality in very elderly patients (aged 80 years or older) with acute heart failure by evaluating their SOBASAP score.

\section{Materials and Methods}

This single-hospital retrospective observational study was conducted at the Hitachiomiya Saiseikai Hospital, Japan. We reviewed the medical records of all consecutive patients with heart failure admitted to our hospital between January 2017 and December 2019. The inclusion criteria were as follows: (1) hospitalized patients aged $\geq 80$ years and diagnosed with heart failure, (2) clinical status corresponding to heart failure, according to the Framingham criteria [15], and (3) left ventricular function assessed with echocardiography, at least. The exclusion criteria were as follows: (1) brain natriuretic peptide (BNP) level $<100 \mathrm{pg} / \mathrm{mL}$ or unknown, (2) readmission of the same patient with acute heart failure, (3) no diagnosis of acute heart failure, and (4) requiring transfer to a tertiary hospital. We divided the participants into two groups based on the prevalence of in-hospital mortality: the survivor group and the non-survivor group.

This study was approved by our institutional review board (ID 20-06) and was conducted in accordance with the Declaration of Helsinki for experiments involving humans. The requirement for written informed consent was waived by our institutional review board due to the retrospective nature of the study.

In echocardiography, data acquisition was performed by an expert. The variables measured and derived using echocardiography were determined as follows: two-dimensional left ventricular ejection fraction (LVEF) was computed from the calculated left ventricular end-diastolic and end-systolic volumes. Valvular heart disease was defined as moderate to severe valvular disease (according to current guidelines [16-18]) or a history of valvular surgery or cardiac surgery. Wall motion abnormality was defined as localized abnormal wall motion, such as akinesis, hypokinesis, and dyskinesis.

Hypertension was defined as the use of medication for hypertension and/or a history of hypertension before admission. Dyslipidemia was defined as a triglyceride level $\geq 150 \mathrm{mg} / \mathrm{dL}$, low-density lipoprotein cholesterol level $\geq 140 \mathrm{mg} / \mathrm{dL}$, high-density lipoprotein cholesterol level $\leq 40 \mathrm{mg} / \mathrm{dL}$, the use of medication for dyslipidemia, or a history of dyslipidemia. Diabetes mellitus was defined as a hemoglobin A1c level $\geq 6.5 \%$ (National Glycohemoglobin Standardization Program value), the use of medication for diabetes mellitus, or a history of diabetes mellitus. Chronic obstructive pulmonary disease (COPD) was defined as the use of medical treatment for COPD and/or a history of COPD before admission. We calculated the estimated glomerular filtration rate (eGFR) from the serum creatinine levels, age, weight, and sex using the following formula: eGFR $\left(\mathrm{mL} / \mathrm{min} / 1.73 \mathrm{~m}^{2}\right)=194 \times \mathrm{s}-\mathrm{Cr}(-1.094) \times$ age $(-0.287) \times 0.739$ (if female) [19]. Worsening renal function was defined as an increase in the serum creatinine level to $>0.3 \mathrm{mg} / \mathrm{dL}$ [20]. The SOB-ASAP score was calculated according to the previously published formula [14].

\section{Statistical Analyses}

All statistical analyses were performed using SPSS 26.0 for Windows (SPSS, Chicago, IL, USA).

Continuous data are expressed as mean \pm standard deviation (SD). Normality was tested using the Shapiro-Wilk test. Normally distributed continuous variables were compared between the two groups using the unpaired Student's $t$-test. Continuous variables were compared using the Mann-Whitney $U$-test. Categorical variables were expressed as numbers and percentages and were compared using the Pearson's $\chi^{2}$ test or the Fisher's exact test. Multivariate stepwise regression analysis was used to evaluate the in-hospital mortality in elderly patients (aged $\geq 80$ years) with acute heart failure; the included vari- 
ables were found to be significant $(p<0.1)$ using a univariate logistic regression analysis. We analyzed the relationship between LVEF and the in-hospital mortality by constructing a receiver operating characteristics (ROC) curve and calculating the area under the curve. The area under the curve was 0.66 (95\% confidence interval $(\mathrm{CI}): 0.53-0.79, p=0.018)$. The sensitivity and specificity for an LVEF of $49.6 \%$ were $60.2 \%$ and $39.1 \%$, respectively. Therefore, an $\mathrm{LVEF} \geq 50 \%$ was analyzed in the univariate analysis. Meanwhile, the variables included in the SOB-ASAP scoring system, such as the systolic blood pressure and BNP, were excluded from the multivariate model. A $p$-value $<0.05$ was considered statistically significant.

\section{Results}

A total of 106 patients (36.8\% men, mean age: $89.8 \pm 4.5$ years) were included in the study (survivor group: $n=83$; non-survivor group: $n=23$ ) (Figure 1 ).

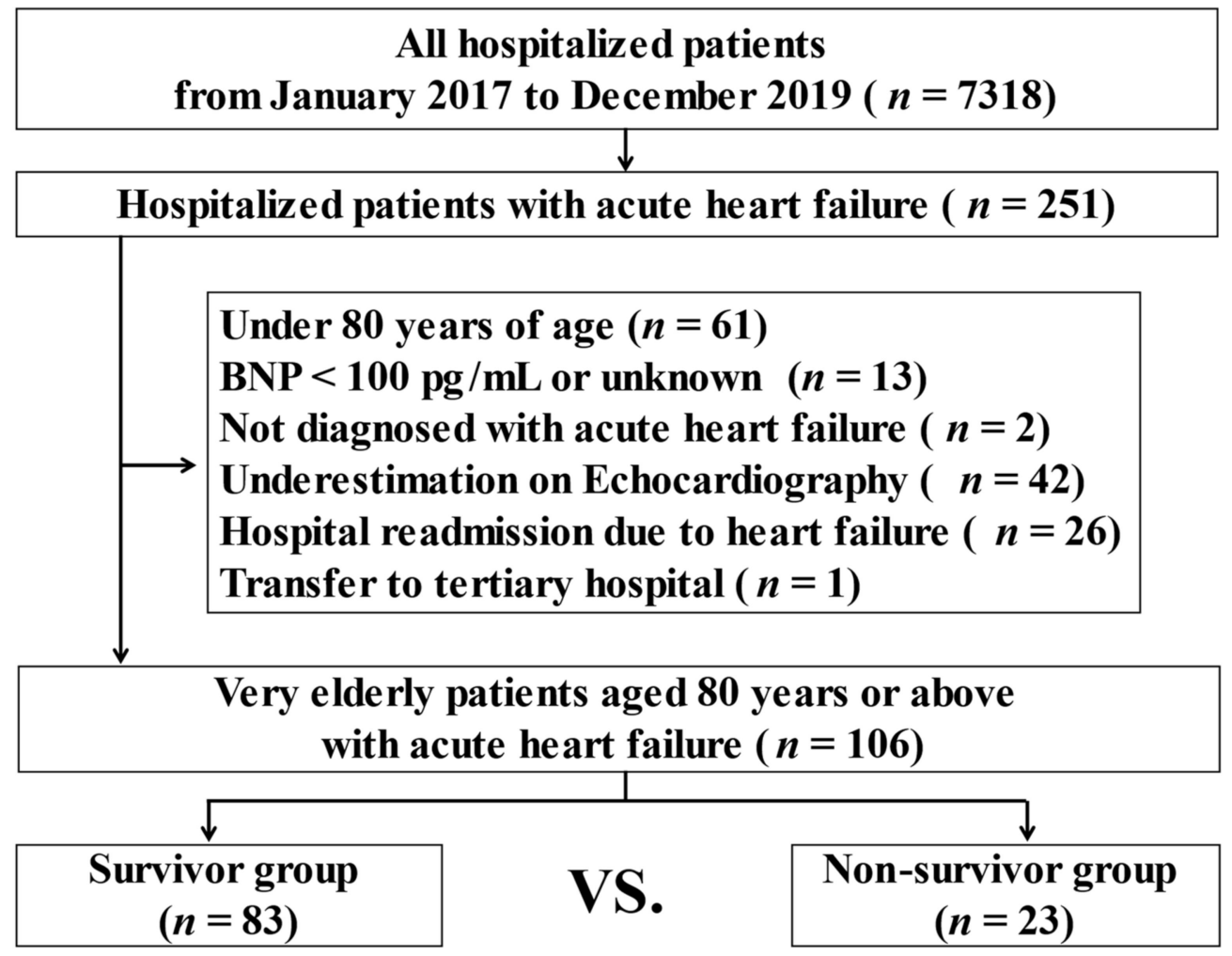

Figure 1. Study flow chart. BNP: brain natriuretic peptide.

Table 1 shows the comparison of the baseline characteristics and medication usage at admission between the two groups. The systolic blood pressure was significantly higher in the survivor group than in the non-survivor group $(139 \pm 33 \mathrm{mmHg}$ vs. $119 \pm 20 \mathrm{mmHg}$, $p=0.011$ ). A systolic blood pressure of $\leq 100 \mathrm{mmHg}$, indicating an unstable hemodynamic status, was more prevalent in the non-survivor group than in the survivor group (26.1\% vs. $8.4 \%, p=0.022)$. The SOB-ASAP score was significantly better in the survivor group than in the non-survivor group $(4.3 \pm 2.3$ vs. $6.8 \pm 2.7, p<0.001)$. Mineralocorticoid receptor antagonist usage was significantly lower in the survivor group than in the non-survivor group $(10.8 \%$ vs. $30.4 \%, p=0.028)$. 
Table 1. Comparison of the baseline characteristics and medication usage at admission between the survivor and nonsurvivor groups.

\begin{tabular}{|c|c|c|c|}
\hline & $\begin{array}{l}\text { Survivor Group } \\
\quad(n=83)\end{array}$ & $\begin{array}{l}\text { Non-Survivor Group } \\
(n=23)\end{array}$ & $p$-Value \\
\hline Age, years & $89.5 \pm 4.6$ & $91.0 \pm 4.2$ & 0.17 \\
\hline Male sex, $n(\%)$ & $31(37.3)$ & $8(34.8)$ & 0.82 \\
\hline Height, $\mathrm{cm}$ & $147 \pm 10$ & $149 \pm 9$ & 0.34 \\
\hline Body weight, $\mathrm{kg}$ & $49.8 \pm 10.6$ & $46.4 \pm 11.0$ & 0.087 \\
\hline Systolic blood pressure, $\mathrm{mmHg}(n, \%)$ & $139 \pm 33$ & $119 \pm 20$ & 0.011 \\
\hline Diastolic blood pressure, $\mathrm{mmHg}(n, \%)$ & $78.5 \pm 23.1$ & $72.0 \pm 16.0$ & 0.35 \\
\hline Heart rate, beats / minute $(n, \%)$ & $89 \pm 26$ & $93 \pm 31$ & 0.41 \\
\hline Respiratory rate, breaths /minute $(n, \%)$ & $21 \pm 6$ & $19 \pm 4$ & 0.13 \\
\hline Systolic blood pressure $\leq 100 \mathrm{mmHg}, n(\%)$ & $7(8.4)$ & $6(26.1)$ & 0.022 \\
\hline Hypertension, $n(\%)$ & $76(91.6)$ & $21(91.3)$ & 0.62 \\
\hline Dyslipidemia, $n(\%)$ & $21(25.3)$ & $5(21.7)$ & 0.48 \\
\hline Diabetes mellitus, $n(\%)$ & $25(30.1)$ & $6(26.1)$ & 0.71 \\
\hline Atrial fibrillation/atrial flutter, $n(\%)$ & $46(55.4)$ & $16(69.6)$ & 0.22 \\
\hline Pacemaker implantation, $n(\%)$ & $13(15.7)$ & $1(4.3)$ & 0.14 \\
\hline Chronic obstructive pulmonary disease, $n(\%)$ & $7(8.4)$ & $2(8.7)$ & 0.62 \\
\hline $\mathrm{eGFR}<60 \mathrm{~mL} / \mathrm{min} / 1.73 \mathrm{~m}^{2}, n(\%)$ & $61(73.5)$ & $16(69.6)$ & 0.71 \\
\hline $\begin{array}{l}\text { Ambulance transport to emergency department, } \\
\qquad(\%)\end{array}$ & $16(19.3)$ & $6(26.1)$ & 0.33 \\
\hline NYHA functional classification at admission & & & 0.32 \\
\hline $3, n(\%)$ & $27(32.5)$ & $5(21.7)$ & \\
\hline $4, n(\%)$ & $56(67.5)$ & $18(78.3)$ & \\
\hline SOB-ASAP score, $(n, \%)$ & $4.3 \pm 2.3$ & $6.8 \pm 2.7$ & $<0.001$ \\
\hline \multicolumn{4}{|l|}{ Medication usage at admission } \\
\hline ACE-I and/or ARB, $n(\%)$ & $47(56.6)$ & $9(39.1)$ & 0.14 \\
\hline$\beta$ blockers, $n(\%)$ & $27(32.5)$ & $7(30.4)$ & 0.85 \\
\hline Calcium channel blockers, $n(\%)$ & $35(42.2)$ & $7(30.4)$ & 0.31 \\
\hline Loop diuretics, $n(\%)$ & $47(56.6)$ & $17(73.9)$ & 0.13 \\
\hline Mineralocorticoid receptor antagonists, $n(\%)$ & $9(10.8)$ & $7(30.4)$ & 0.028 \\
\hline Thiazides, $n(\%)$ & $2(2.4)$ & $2(8.7)$ & 0.21 \\
\hline Tolvaptan, $n(\%)$ & $6(7.2)$ & $3(13.0)$ & 0.30 \\
\hline Digitalis, $n(\%)$ & $4(4.8)$ & $1(4.3)$ & 0.70 \\
\hline PDE3-inhibitor, $n(\%)$ & $1(1.2)$ & $3(13.0)$ & 0.031 \\
\hline Statins, $n(\%)$ & $12(14.5)$ & $3(13.0)$ & 0.58 \\
\hline Oral anti-diabetes mellitus agents, $n(\%)$ & $12(14.5)$ & $2(8.7)$ & 0.37 \\
\hline Anti-platelets, $n(\%)$ & $18(21.7)$ & $8(34.8)$ & 0.20 \\
\hline Anti-coagulants, $n(\%)$ & $27(32.5)$ & $5(21.7)$ & 0.32 \\
\hline
\end{tabular}

Categorical variables are expressed as numbers and percentages. Continuous variables are expressed as mean \pm SD. ACE-I: angiotensinconverting enzyme inhibitor; ARB: angiotensin II receptor blocker; eGFR: estimated glomerular filtration rate; GWTG-HF: Get with the Guideline-Heart Failure; NYHA: New York Heart Association, PDE3: phosphodiesterase 3; SOB-ASAP: SO, serum sodium; B, blood urea nitrogen; A, age and serum albumin; S, systolic blood pressure; and $\mathrm{P}$, natriuretic peptide levels.

Table 2 shows the differences in the baseline laboratory data and echocardiographic parameters between the two groups. The serum sodium levels were significantly higher in the survivor group than in the non-survivor group $(139 \pm 5 \mathrm{mEq} / \mathrm{L}$ vs. $136 \pm 5 \mathrm{mEq} / \mathrm{L}, p=0.025)$. The C-reactive protein level was significantly lower in the survivor group than in the nonsurvivor group $(1.5 \pm 2.3 \mathrm{mg} / \mathrm{dL}$ vs. $5.1 \pm 7.2 \mathrm{mg} / \mathrm{dL}, p=0.0073)$. The BNP level was significantly lower in the survivor group than in the non-survivor group $(646.9 \pm 586.9 \mathrm{pg} / \mathrm{mL}$ vs. $1170.7 \pm 1018.8 \mathrm{pg} / \mathrm{mL}, p=0.0033)$. The LVEF value was significantly better in the survivor group than in the non-survivor group ( $52.8 \pm 17.5 \%$ vs. $42.1 \pm 19.9 \%, p=0.018)$. 
Table 2. The comparison of baseline laboratory data and echocardiographic parameters between the survivor and nonsurvivor groups.

\begin{tabular}{|c|c|c|c|}
\hline & $\begin{array}{l}\text { Survivor Group } \\
\quad(n=83)\end{array}$ & $\begin{array}{l}\text { Non-Survivor Group } \\
(n=23)\end{array}$ & $p$-Value \\
\hline \multicolumn{4}{|l|}{ Laboratory data } \\
\hline Total protein, g/dL $(n, \%)$ & $6.6 \pm 0.7(80,96.4)$ & $6.4 \pm 0.8(22,95.7)$ & 0.22 \\
\hline Serum albumin, $\mathrm{g} / \mathrm{dL}(n, \%)$ & $3.4 \pm 0.5$ & $3.1 \pm 0.7$ & 0.10 \\
\hline Total bilirubin, $\mathrm{g} / \mathrm{dL}(n, \%)$ & $0.79 \pm 0.51(82,98.8)$ & $0.76 \pm 0.40(22,95.7)$ & 0.10 \\
\hline Aspartate aminotransferase, U/L $(n, \%)$ & $37 \pm 32$ & $83 \pm 152$ & 0.70 \\
\hline Alanine aminotransferase, $\mathrm{U} / \mathrm{L}(n, \%)$ & $23 \pm 17$ & $51 \pm 93$ & 0.99 \\
\hline Serum sodium, $\mathrm{mEq} / \mathrm{L}(n, \%)$ & $139 \pm 5$ & $136 \pm 5$ & 0.025 \\
\hline Serum potassium, $\mathrm{mEq} / \mathrm{L}(n, \%)$ & $4.2 \pm 0.7$ & $4.4 \pm 1.0$ & 0.17 \\
\hline Blood glucose, $\mathrm{mg} / \mathrm{dL}(n, \%)$ & $139 \pm 44(81,90.4)$ & $151 \pm 55(21,91.3)$ & 0.12 \\
\hline Blood urea nitrogen, $\mathrm{mg} / \mathrm{dL}(n, \%)$ & $26.5 \pm 16.5$ & $29.1 \pm 16.6$ & 0.29 \\
\hline Serum creatinine, $\mathrm{mg} / \mathrm{dL}(n, \%)$ & $1.24 \pm 0.76$ & $1.25 \pm 0.60$ & 0.53 \\
\hline $\begin{array}{l}\text { Estimated glomerular filtration rate, } \\
\mathrm{mL} / \mathrm{min} / 1.73 \mathrm{~m}^{2}(n, \%)\end{array}$ & $47.2 \pm 23.3$ & $43.4 \pm 20.5$ & 0.59 \\
\hline C-reactive protein, $\mathrm{mg} / \mathrm{dL}(n, \%)$ & $1.5 \pm 2.3$ & $5.1 \pm 7.2$ & 0.0073 \\
\hline Hemoglobin, g/dL $(n, \%)$ & $10.9 \pm 2.0$ & $11.0 \pm 1.9$ & 0.81 \\
\hline Brain natriuretic peptide, $\mathrm{pg} / \mathrm{mL}(n, \%)$ & $646.9 \pm 586.9$ & $1170.7 \pm 1018.8$ & 0.0033 \\
\hline \multicolumn{4}{|l|}{ Echocardiography results } \\
\hline Left ventricular ejection fraction, $(\%)$ & $52.9 \pm 17.5$ & $42.1 \pm 19.9$ & 0.018 \\
\hline Interventricular septal thickness, mm & $9.7 \pm 1.7(82,98.8)$ & $9.6 \pm 2.9(22,95.7)$ & 0.36 \\
\hline Left ventricular end-diastolic diameter, $\mathrm{mm}$ & $44.9 \pm 8.8$ & $45.6 \pm 11.6$ & 0.95 \\
\hline Left ventricular end-systolic diameter, mm & $32.4 \pm 9.4$ & $36.3 \pm 12.6$ & 0.30 \\
\hline Posterior left ventricular wall thickness, $\mathrm{mm}$ & $9.8 \pm 1.9(88,98.8)$ & $10.0 \pm 2.2(22,95.7)$ & 0.71 \\
\hline Left ventricular end-diastolic volume, mL & $95.9 \pm 44.3$ & $103.7 \pm 60.9$ & 0.98 \\
\hline Left ventricular end-systolic volume, $\mathrm{mL}$ & $47.3 \pm 32.4$ & $65.6 \pm 51.2$ & 0.28 \\
\hline Left atrial diameter, $\mathrm{mm}$ & $43.1 \pm 9.4(82,98.8)$ & $41.8 \pm 8.2$ & 0.56 \\
\hline Aortic diameter, mm & $29.7 \pm 4.2(80,96.4)$ & $31.8 \pm 5.2$ & 0.078 \\
\hline Valvular heart disease, $n(\%)$ & $74(89.2)$ & $22(95.7)$ & 0.31 \\
\hline Wall motion abnormality, $n(\%)$ & $9(10.8)$ & $4(17.4)$ & 0.30 \\
\hline
\end{tabular}

Categorical variables are expressed as numbers and percentages. Continuous variables are expressed as mean \pm standard deviation (SD).

Table 3 shows the comparison of treatment strategies and subsequent outcomes during hospitalization between the two groups. The prevalence of intravenous administration of diuretics within $48 \mathrm{~h}$ of hospitalization was significantly higher in the survivor group than in the non-survivor group ( $80.7 \%$ vs. $56.5 \%, p=0.017)$. The prevalence of intravenous catecholamine support requirement and intravenous administration of antibiotics within $48 \mathrm{~h}$ of hospitalization was significantly lower in the survivor group than in the non-survivor group $(1.2 \%$ vs. $13.0 \%, p=0.031 ; 14.5 \%$ vs. $34.8 \%, p=0.033$, respectively). Intravenous catecholamine support requirement, intravenous administration of antibiotics, and noninvasive positive pressure ventilation support during the entire period of hospitalization were more prevalent in the non-survivor group than in the survivor group (3.4\% vs. $30.4 \%$, $p<0.001 ; 18.0 \%$ vs. $52.2 \%, p<0.001$; and $5.6 \%$ vs. $21.7 \%, p=0.029$, respectively). Worsening of renal function was less frequent in the survivor group than in the non-survivor group $(21.3 \%$ vs. $60.9 \%, p<0.001)$. 
Table 3. Comparison of treatment and outcomes during hospitalization between the survivor and non-survivor groups.

\begin{tabular}{|c|c|c|c|}
\hline & $\begin{array}{l}\text { Survivor Group } \\
\quad(n=83)\end{array}$ & $\begin{array}{l}\text { Non-Survivor Group } \\
\qquad(n=23)\end{array}$ & $p$-Value \\
\hline \multicolumn{4}{|l|}{ Details of treatment within $48 \mathrm{~h}$ of hospitalization } \\
\hline Intravenous diuretic administration, $n(\%)$ & $67(80.7)$ & $13(56.5)$ & 0.017 \\
\hline Intravenous carperitide administration, $n(\%)$ & $1(1.2)$ & $0(0.0)$ & 0.78 \\
\hline Tolvaptan introduction, $n(\%)$ & $5(6.0)$ & $0(0.0)$ & 0.29 \\
\hline Intravenous nitric acid administration, $n(\%)$ & $11(13.0)$ & $1(4.3)$ & 0.21 \\
\hline Digoxin administration, $n(\%)$ & $3(3.6)$ & $2(8.7)$ & 0.30 \\
\hline Intravenous catecholamine support requirement, $n(\%)$ & $1(1.2)$ & $3(13.0)$ & 0.031 \\
\hline Oral PDE3-inhibitor and/or catecholamine addition $n(\%)$ & $0(0.0)$ & $1(4.3)$ & 0.22 \\
\hline Intravenous antibiotic administration, $n(\%)$ & $12(14.5)$ & $8(34.8)$ & 0.033 \\
\hline NPPV support requirement, $n(\%)$ & $4(4.8)$ & $3(13.0)$ & 0.17 \\
\hline Morphine use, $n(\%)$ & $2(2.4)$ & $0(0.0)$ & 0.61 \\
\hline \multicolumn{4}{|c|}{ Details of treatment and results during the entire period of hospitalization } \\
\hline Intravenous diuretic administration, $n(\%)$ & $74(83.1)$ & $19(82.6)$ & 0.58 \\
\hline Intravenous carperitide administration, $n(\%)$ & $1(1.1)$ & $0(0.0)$ & 0.80 \\
\hline Tolvaptan introduction, $n(\%)$ & $11(12.4)$ & $6(26.1)$ & 0.099 \\
\hline Intravenous nitric acid administration, $n(\%)$ & $13(14.6)$ & $1(4.3)$ & 0.17 \\
\hline Digoxin administration, $n(\%)$ & $5(5.6)$ & $2(8.7)$ & 0.44 \\
\hline Intravenous catecholamine support requirement, $n(\%)$ & $3(3.4)$ & $7(30.4)$ & $<0.001$ \\
\hline $\begin{array}{l}\text { Oral PDE3-inhibitor and/or catecholamine } \\
\text { administration, } n(\%)\end{array}$ & $3(3.4)$ & $2(8.7)$ & 0.27 \\
\hline Intravenous antibiotic administration, $n(\%)$ & $16(18.0)$ & $12(52.2)$ & $<0.001$ \\
\hline NPPV support requirement, $n(\%)$ & $5(5.6)$ & $5(21.7)$ & 0.029 \\
\hline Morphine use, $n(\%)$ & $1(1.1)$ & $2(8.7)$ & 0.11 \\
\hline $\begin{array}{l}\text { Maximum serum creatinine during hospitalization, } \\
\qquad \mathrm{mg} / \mathrm{dL}(n, \%)\end{array}$ & $1.47 \pm 0.96$ & $2.03 \pm 1.10$ & 0.0089 \\
\hline Worsening renal function, $n(\%)$ & $19(21.3)$ & $14(60.9)$ & $<0.001$ \\
\hline
\end{tabular}

Categorical variables are expressed as numbers and percentages. Continuous variables are expressed as mean \pm SD. NPPV: noninvasive positive pressure ventilation; PDE3: phosphodiesterase 3.

Table 4 shows the results of the univariate logistic regression analysis and the multivariate stepwise regression analysis for predicting in-hospital mortality. Only variables that had significant differences ( $p$-value $<0.1)$, except for age and male sex, are shown in the results of the univariate logistic regression analysis (Supplemental Table S1). The multivariate stepwise regression analysis model showed that a poor SOB-ASAP score (per point increase; odds ratio (OR): $1.449,95 \%$ CI: $1.159-1.812, p=0.0010)$, oral phosphodiesterase 3 inhibitor usage at admission (OR: 14.276, 95\% CI: 1.119-182.170, $p=0.041$ ), and intravenous antibiotic administration within $48 \mathrm{~h}$ of hospitalization (OR: 3.887, 95\% CI: $1.142-13.224, p=0.030$ ) were significantly associated with in-hospital mortality.

Table 4. Results of the univariate logistic regression analysis and the multivariate stepwise regression analysis for predicting in-hospital mortality.

\begin{tabular}{|c|c|c|c|}
\hline Univariate Analysis & OR & $95 \% \mathrm{CI}$ & $p$-Value \\
\hline Age (per year increase) & 1.077 & $0.969-1.197$ & 0.17 \\
\hline Male sex & 0.897 & $0.340-2.352$ & 0.82 \\
\hline Systolic blood pressure (per $\mathrm{mmHg}$ increase) & 0.975 & $0.956-0.993$ & 0.0086 \\
\hline SOB-ASAP score (per point increase) & 1.455 & $1.194-1.774$ & $<0.001$ \\
\hline Mineralocorticoid receptor antagonist use at admission & 3.597 & $1.167-11.090$ & 0.026 \\
\hline Phosphodiesterase 3 inhibitor use at admission & 12.300 & $1.214-124.581$ & 0.034 \\
\hline Serum albumin (per g/dL increase) & 0.462 & $0.204-1.044$ & 0.063 \\
\hline Aspartate aminotransferase (per U/L increase) & 1.007 & 0.999-1.015 & 0.079 \\
\hline Alanine aminotransferase (per U/L increase) & 1.012 & $0.998-1.025$ & 0.083 \\
\hline Serum sodium (per mEq/L increase) & 0.917 & $0.838-1.004$ & 0.060 \\
\hline
\end{tabular}


Table 4. Cont.

\begin{tabular}{|c|c|c|c|}
\hline Univariate Analysis & OR & $95 \% \mathrm{CI}$ & $p$-Value \\
\hline Serum potassium (per mEq/L increase) & 1.716 & $0.926-3.182$ & 0.086 \\
\hline C-reactive protein (per $\mathrm{mg} / \mathrm{dL}$ increase) & 1.267 & $1.087-1.486$ & 0.0036 \\
\hline Brain natriuretic peptide (per pg/mL increase) & 1.001 & $1.000-1.001$ & 0.0080 \\
\hline Left ventricular end-systolic volume (per mL increase) & 1.012 & $1.000-1.023$ & 0.046 \\
\hline Left ventricular ejection fraction $\geq 50 \%$ & 0.446 & $0.173-1.147$ & 0.094 \\
\hline Aortic diameter (per mm increase) & 1.101 & $0.997-1.216$ & 0.058 \\
\hline Intravenous diuretic administration within $48 \mathrm{~h}$ of hospitalization & 0.310 & $0.116-0.834$ & 0.020 \\
\hline Catecholamine support requirement within $48 \mathrm{~h}$ of hospitalization & 12.300 & $1.214-124.581$ & 0.034 \\
\hline Intravenous antibiotic administration within $48 \mathrm{~h}$ of hospitalization & 3.156 & $1.100-9.052$ & 0.033 \\
\hline Multivariate Analysis & OR & $95 \% \mathrm{CI}$ & $p$-Value \\
\hline SOB-ASAP score (per point increase) & 1.449 & $1.159-1.812$ & 0.0010 \\
\hline Phosphodiesterase 3 inhibitor use at admission & 14.276 & $1.119-182.170$ & 0.041 \\
\hline Intravenous antibiotic administration within $48 \mathrm{~h}$ of hospitalization & 3.887 & $1.142-13.224$ & 0.030 \\
\hline
\end{tabular}

CI: confidence interval; GWTG-HF: Get with the Guideline-Heart Failure; NPPV: noninvasive positive pressure ventilation; NYHA: New York Heart Association; OR: odds ratio; SOB-ASAP: SO, serum sodium; B, blood urea nitrogen; A, age and serum albumin; S, systolic blood pressure; and $\mathrm{P}$, natriuretic peptide levels.

\section{Discussion}

The three main findings of the present study are as follows: (1) the SOB-ASAP score can predict in-hospital mortality even in very elderly patients with acute heart failure, and (2) in addition to the SOB-ASAP score, use of oral phosphodiesterase 3 inhibitors at admission, and requirement of intravenous antibiotic administration within $48 \mathrm{~h}$ of hospitalization were important factors for predicting in-hospital mortality secondary to acute heart failure.

The SOB-ASAP score, which can predict the clinical outcomes of patients with acute heart failure, was found to be useful and practical. Several previous studies have performed risk assessments for patients with heart failure, including assessments with the Get with the Guideline-Heart Failure (GWTG-HF) risk score that was adopted globally to anticipate the outcomes of acute heart failure [21]. Although the SOB-ASAP score was validated in accordance with previous risk scores such as the GWTG-HF risk score, the SOB-ASAP score includes novel serum parameters such as BNP and N-terminal pro-BNP (NT-pro BNP), which were not considered in the previous studies [14]. Therefore, the SOB-ASAP score may predict the outcomes of hospitalized patients with acute heart failure. Furthermore, one of the greatest advantages of the SOB-ASAP score is that it predicts the clinical outcomes of patients with acute heart failure during the very acute phase of hospitalization [14]. The present study suggests the usefulness of a novel risk scoring system even in very elderly patients with acute heart failure, which could be valuable for physicians treating patients with heart failure.

The present study also underscores the clinical impact of treatment with oral phosphodiesterase 3 inhibitors at admission. Phosphodiesterase 3 inhibitors are often required in patients with heart failure having a severe clinical status [22]. One study showed that despite their hemodynamically beneficial effects, long-term therapy with oral phosphodiesterase 3 inhibitors could increase the morbidity and mortality of patients with severe chronic heart failure [23]. In other words, patients treated with oral phosphodiesterase 3 inhibitors are in a worse clinical situation. Therefore, in-hospital mortality could be frequently observed in patients with acute heart failure requiring oral phosphodiesterase 3 inhibitors.

The association between intravenous antibiotic administration within $48 \mathrm{~h}$ of hospitalization and worse clinical outcomes should be discussed further. The present study showed that patients who required intravenous antibiotic administration in the early phase of hospitalization were often suspected of being affected with pneumonia, because patients with worse clinical outcomes had higher serum C-reactive protein levels as well as symptoms similar to that of pneumonia. Furthermore, a previous study showed that the 
coexistence of comorbidities, such as pneumonia, could increase the risk of mortality in the elderly [24,25]. The requirement of intravenous antibiotic administration in the early phase of hospitalization could lead to acute infections such as pneumonia, and could therefore affect the clinical outcomes of elderly patients with heart failure.

Our study has several limitations. First, because this was a single-center retrospective observational study, there is a risk of selection bias. Second, although both left and right cardiac function may affect the clinical prognosis [26,27], the present study did not comprehensively assess the cardiac function. Moreover, the present study did not show the etiology of heart failure. Furthermore, the prognosis of patients with heart failure having a preserved ejection fraction (HFpEF) was as bad as that of patients with heart failure having a reduced ejection fraction (HFrEF). Additionally, the prevalence of HFpEF was high in the elderly patients with heart failure $[28,29]$. Therefore, the relationship between LVEF and prognosis should be carefully interpreted. Third, the frailty and nutritional status of patients could affect their prognosis [30,31]; however, we could not obtain sufficient information on the baseline frailty and nutritional status due to the severity of acute heart failure and its emergent clinical setting. Fourth, the severity of acute heart failure itself might affect the selection of treatment. For example, in some cases, physicians may hesitate to administer intravenous diuretics due to unstable hemodynamics. Finally, the present study was observational in nature and had a relatively small study population; therefore, it can be considered as a pilot study whose results need to be confirmed prospectively in further extensive multicenter studies.

In conclusion, a poor SOB-ASAP score, oral phosphodiesterase 3 inhibitor use at admission, and requirement of early intravenous antibiotic administration were significantly associated with in-hospital mortality in elderly patients (aged $\geq 80$ years) with acute heart failure. Recognizing patients with severe disease and high SOB-ASAP scores, which is a novel risk scoring system, could help physicians to treat patients with heart failure.

Supplementary Materials: The following are available online at https:/ / www.mdpi.com/article/10 .3390/jcm10071468/s1, Table S1: Univariate logistic regression analysis to predict in-hospital mortality.

Author Contributions: Conceptualization, Methodology, Original draft preparation, Data curation, and writing: Y.W. Editing, Supervision, Reviewing Writing, and Investigation: K.T. Supervision and Editing: H.N. Supervision and Reviewing: M.K. All authors have read and agreed to the published version of the manuscript.

Funding: This research received no external funding.

Institutional Review Board Statement: The study was conducted according to the guidelines of the Declaration of Helsinki and was approved by the Institutional Review Board of the Hitachiomiya Hospital (ID 20-06).

Informed Consent Statement: Patient consent was waived due to the retrospective nature of the study.

Data Availability Statement: The datasets generated and/or analyzed during the current study are not publicly available because the study dataset contains potentially identifying clinical information, but are available from the corresponding author upon reasonable request.

Acknowledgments: We are grateful to the staff of the clinical laboratory department at the Hitachiomiya Saiseikai Hospital for their support.

Conflicts of Interest: The authors declare no conflict of interest. The funders had no role in the design of the study; in the collection, analyses, or interpretation of data; in the writing of the manuscript, or in the decision to publish the results. 


\section{References}

1. Virani, S.S.; Alonso, A.; Benjamin, E.J.; Bittencourt, M.S.; Callaway, C.W.; Carson, A.P.; Chamberlain, A.M.; Chang, A.R.; Cheng, S.; Delling, F.N.; et al. Heart disease and stroke statistics-2020 update: A report from the American Heart Association. Circulation 2020, 141, e139-e596. [CrossRef] [PubMed]

2. Ambrosy, A.P.; Fonarow, G.C.; Butler, J.; Chioncel, O.; Greene, S.J.; Vaduganathan, M.; Nodari, S.; Lam, C.S.P.; Sato, N.; Shah, A.N.; et al. The global health and economic burden of hospitalizations for heart failure: Lessons learned from hospitalized heart failure registries. J. Am. Coll. Cardiol. 2014, 63, 1123-1133. [CrossRef] [PubMed]

3. Sidney, S.; Go, A.S.; Jaffe, M.G.; Solomon, M.D.; Ambrosy, A.P.; Rana, J.S. Association between aging of the US population and heart disease mortality from 2011 to 2017. JAMA Cardiol. 2019, 4, 1280-1286. [CrossRef] [PubMed]

4. Takahashi, T.; Morisawa, T.; Saitoh, M.; Yokoyama, M.; Shimada, K.; Fujiwara, T.; Daida, H. Current status and future development of acute and cardiac physiotherapies in Japan. Phys. Ther. Res. 2020, 23, 1-7. [CrossRef]

5. Yancy, C.W.; Jessup, M.; Bozkurt, B.; Butler, J.; Casey, D.E., Jr.; Drazner, M.H.; Fonarow, G.C.; Geraci, S.A.; Horwich, T.; Januzzi, J.L.; et al. 2013 ACCF/AHA guideline for the management of heart failure: A report of the American College of Cardiology Foundation/American Heart Association Task Force on practice guidelines. Circulation 2013, 128, e240-e327. [CrossRef]

6. Stiell, I.G.; Perry, J.J.; Clement, C.M.; Brison, R.J.; Rowe, B.H.; Aaron, S.D.; McRae, A.D.; Borgundvaag, B.; Calder, L.A.; Forster, A.J.; et al. Prospective and explicit clinical validation of the Ottawa heart failure risk scale, with and without use of quantitative NT-proBNP. Acad. Emerg. Med. 2017, 24, 316-327. [CrossRef]

7. Lee, D.S.; Stitt, A.; Austin, P.C.; Stukel, T.A.; Schull, M.J.; Chong, A.; Newton, G.E.; Lee, J.S.; Tu, J.V. Prediction of heart failure mortality in emergent care: A cohort study. Ann. Intern. Med. 2012, 156, 767-775. [CrossRef] [PubMed]

8. Miró, Ó.; Pocock, S.J. Predicting 30-day mortality for patients with acute heart failure in the emergency department. Ann. Intern. Med. 2018, 168, 899-900. [CrossRef]

9. Campanile, A.; Castellani, C.; Santucci, A.; Annunziata, R.; Tutarini, C.; Reccia, M.R.; Del Pinto, M.; Verdecchia, P.; Cavallini, C. Predictors of in-hospital and long-term mortality in unselected patients admitted to a modern coronary care unit. J. Cardiovasc. Med. 2019, 20, 327-334. [CrossRef] [PubMed]

10. Rivero-Ayerza, M.; Scholte Op Reimer, W.; Lenzen, M.; Theuns, D.A.; Jordaens, L.; Komajda, M.; Follath, F.; Swedberg, K.; Cleland, J.G. New-onset atrial fibrillation is an independent predictor of in-hospital mortality in hospitalized heart failure patients: Results of the EuroHeart Failure Survey. Eur. Heart J. 2008, 29, 1618-1624. [CrossRef]

11. Alataş, Ö.D.; Biteker, M.; Yildirim, B.; Acar, E.; Gökçek, K. Comparison of objective nutritional indexes for the prediction of in-hospital mortality among elderly patients with acute heart failure. Eur. J. Emerg. Med. 2020, 27, 362-367. [CrossRef]

12. Flather, M.D.; Shibata, M.C.; Coats, A.J.; Van Veldhuisen, D.J.; Parkhomenko, A.; Borbola, J.; Cohen-Solal, A.; Dumitrascu, D.; Ferrari, R.; Lechat, P.; et al. Randomized trial to determine the effect of nebivolol on mortality and cardiovascular hospital admission in elderly patients with heart failure (SENIORS). Eur. Heart J. 2005, 26, 215-225. [CrossRef]

13. Düngen, H.D.; Apostolovic, S.; Inkrot, S.; Tahirovic, E.; Töpper, A.; Mehrhof, F.; Prettin, C.; Putnikovic, B.; Neskovic, A.N.; Krotin, M.; et al. Titration to target dose of bisoprolol vs. carvedilol in elderly patients with heart failure: The CIBIS-ELD trial. Eur. J. Heart Fail. 2011, 13, 670-680. [CrossRef] [PubMed]

14. Shiraishi, Y.; Kohsaka, S.; Abe, T.; Nagai, T.; Goda, A.; Nishihata, Y.; Nagatomo, Y.; Saji, M.; Toyosaki, Y.; Takei, M.; et al. Derivation and validation of clinical prediction models for rapid risk stratification for time-sensitive management for acute heart failure. J. Clin. Med. 2020, 9, 3394. [CrossRef]

15. McKee, P.A.; Castelli, W.P.; McNamara, P.M.; Kannel, W.B. The natural history of congestive heart failure: The Framingham study. N. Engl. J. Med. 1971, 285, 1441-1446. [CrossRef]

16. Baumgartner, H.; Hung, J.; Bermejo, J.; Chambers, J.B.; Edvardsen, T.; Goldstein, S.; Lancellotti, P.; LeFevre, M.; Miller, F., Jr.; Otto, C.M. Recommendations on the echocardiographic assessment of aortic valve stenosis: A focused update from the European Association of Cardiovascular Imaging and the American Society of Echocardiography. J. Am. Soc. Echocardiogr. $2017,30,372-392$. [CrossRef] [PubMed]

17. Zoghbi, W.A.; Adams, D.; Bonow, R.O.; Enriquez-Sarano, M.; Foster, E.; Grayburn, P.A.; Hahn, R.T.; Han, Y.; Hung, J.; Lang, R.M.; et al. Recommendations for noninvasive evaluation of native valvular regurgitation: A report from the American Society of Echocardiography Developed in Collaboration with the Society for Cardiovascular Magnetic Resonance. J. Am. Soc. Echocardiogr. 2017, 30, 303-371. [CrossRef] [PubMed]

18. Baumgartner, H.; Hung, J.; Bermejo, J.; Chambers, J.B.; Evangelista, A.; Griffin, B.P.; Iung, B.; Otto, C.M.; Pellikka, P.A.; Quiñones, M. Echocardiographic assessment of valve stenosis: EAE/ASE recommendations for clinical practice. J. Am. Soc. Echocardiogr. 2009, 22, 1-23. [CrossRef]

19. Matsuo, S.; Imai, E.; Horio, M.; Yasuda, Y.; Tomita, K.; Nitta, K.; Yamagata, K.; Tomino, Y.; Yokoyama, H.; Hishida, A. Revised equations for estimated GFR from serum creatinine in Japan. Am. J. Kidney Dis. 2009, 53, 982-992. [CrossRef]

20. Damman, K.; Valente, M.A.; Voors, A.A.; O'Connor, C.M.; van Veldhuisen, D.J.; Hillege, H.L. Renal impairment, worsening renal function, and outcome in patients with heart failure: An updated meta-analysis. Eur. Heart J. 2014, 35, 455-469. [CrossRef]

21. Peterson, P.N.; Rumsfeld, J.S.; Liang, L.; Albert, N.M.; Hernandez, A.F.; Peterson, E.D.; Fonarow, G.C.; Masoudi, F.A. A validated risk score for in-hospital mortality in patients with heart failure from the American Heart Association get with the guidelines program. Circ. Cardiovasc. Qual. Outcomes 2010, 3, 25-32. [CrossRef] 
22. Dobashi, S.; Watanabe, I.; Nakanishi, R.; Hisatake, S.; Kiuchi, S.; Kabuki, T.; Oka, T.; Fujii, T.; Ikeda, T. Comparing the effects of milrinone and olprinone in patients with congestive heart failure. Heart Vessel. 2020, 35, 776-785. [CrossRef] [PubMed]

23. Packer, M.; Carver, J.R.; Rodeheffer, R.J.; Ivanhoe, R.J.; DiBianco, R.; Zeldis, S.M.; Hendrix, G.H.; Bommer, W.J.; Elkayam, U.; Kukin, M.L.; et al. Effect of oral milrinone on mortality in severe chronic heart failure. The PROMISE Study Research Group. N. Engl. J. Med. 1991, 325, 1468-1475. [CrossRef]

24. Bahadir, A.; Ortakoylu, M.G.; Iliaz, S.; Kanmaz, Z.D.; Bagci, B.A.; Iliaz, R.; Caglar, E. Prevalence and outcomes of comorbid illnesses in elderly patients with respiratory diseases. Geriatr. Gerontol. Int. 2016, 16, 791-796. [CrossRef]

25. Nakagawa, N.; Saito, Y.; Sasaki, M.; Tsuda, Y.; Mochizuki, H.; Takahashi, H. Comparison of clinical profile in elderly patients with nursing and healthcare-associated pneumonia, and those with community-acquired pneumonia. Geriatr. Gerontol. Int. 2014, 14, 362-371. [CrossRef]

26. Damy, T.; Viallet, C.; Lairez, O.; Deswarte, G.; Paulino, A.; Maison, P.; Vermes, E.; Gueret, P.; Adnot, S.; Dubois-Randé, J.L.; et al. Comparison of four right ventricular systolic echocardiographic parameters to predict adverse outcomes in chronic heart failure. Eur. J. Heart Fail. 2009, 11, 818-824. [CrossRef]

27. Gavazzoni, M.; Badano, L.P.; Vizzardi, E.; Raddino, R.; Genovese, D.; Taramasso, M.; Sciatti, E.; Palermo, C.; Metra, M.; Muraru, D. Prognostic value of right ventricular free wall longitudinal strain in a large cohort of outpatients with left-side heart disease. Eur. Heart J. Cardiovasc. Imaging 2020, 21, 1013-1021. [CrossRef] [PubMed]

28. The survival of patients with heart failure with preserved or reduced left ventricular ejection fraction: An individual patient data meta-analysis. Eur. Heart J. 2012, 33, 1750-1757. [CrossRef]

29. Tsuchihashi-Makaya, M.; Hamaguchi, S.; Kinugawa, S.; Yokota, T.; Goto, D.; Yokoshiki, H.; Kato, N.; Takeshita, A.; Tsutsui, H.; JCARE-CARD Investigators. Characteristics and outcomes of hospitalized patients with heart failure and reduced vs preserved ejection fraction. Report from the Japanese Cardiac Registry of Heart Failure in Cardiology (JCARE-CARD). Circ. J. 2009, 73, 1893-1900. [CrossRef] [PubMed]

30. Nochioka, K.; Sakata, Y.; Takahashi, J.; Miyata, S.; Miura, M.; Takada, T.; Fukumoto, Y.; Shiba, N.; Shimokawa, H. Prognostic impact of nutritional status in asymptomatic patients with cardiac diseases: A report from the CHART-2 Study. Circ. J. 2013, 77, 2318-2326. [CrossRef] [PubMed]

31. Narumi, T.; Watanabe, T.; Kadowaki, S.; Takahashi, T.; Yokoyama, M.; Kinoshita, D.; Honda, Y.; Funayama, A.; Nishiyama, S.; Takahashi, H.; et al. Sarcopenia evaluated by fat-free mass index is an important prognostic factor in patients with chronic heart failure. Eur. J. Intern. Med. 2015, 26, 118-122. [CrossRef] [PubMed] 